\title{
EVALUASI PENATAAN RUANG KAWASAN PENGRAJIN KERAMIK BERWAWASAN LINGKUNGAN PERILAKU DI KELURAHAN DINOYO, KOTA MALANG
}

\author{
Adhi Widyarthara \\ Dosen Prodi Arsitektur, Fak. Teknik Sipil dan Perencanaan, ITN Malang \\ e-mail: Adhiwidyarthara@gmail.com \\ Didiek Suharjanto \\ Dosen Prodi Arsitektur, Fak. Teknik Sipil dan Perencanaan, ITN Malang \\ e-mail: suharjantodidiek@gmail.com \\ Hamka \\ Dosen Prodi Arsitektur, Fak. Teknik Sipil dan Perencanaan, ITN Malang \\ e-mail: hamka07@lecturer.itn.ac.id
}

\begin{abstract}
ABSTRAK
Pengrajin keramik memiliki aktivitas yang spesifik yakni membuat dan menjual produk keramik, kegiatan tersebut membutuhkan ruang yang tertata dengan baik agar proses produksinya lebih efektif dan efisien. Keberadaan ruang yang saat ini digunakan untuk tempat produksi maupun ruang pamer merupakan alih fungsi ruang, yang dulu merupakan bagian dari rumah tinggal; saat ini difungsikan secara optimal dan kondisi ini merupakan produk rancangan tata ruang oleh masyarakat. Evaluasi penataan ruang bertujuan untuk mengetahui kinerja rancangan tata ruang pada saat ini, sehingga dapat memberikan saran apabila didapatkan permasalahan dan mempertahankan rancangannya apabila tatanan ruang tersebut sudah memiliki kinerja yang berwawasan lingkungan perilaku.

Terdapat 3 lingkup kajian untuk melakukan evaluasi tersebut, pertama melakukan kajian mikro yakni mengetahui fungsi ruang untuk proses produksi dan ruang pamer, kedua melakukan kajian meso yakni mengetahui tatanan temp at produksi maupun ruang pamer dengan lingkungannya, ketiga melakukan kajian makro yakni mengetahui potensi lingkungan dalam menunjang kawasan pengrajin keramik. Ketiga kajian lingkungan tersebut melibatkan para pemilik tempat produksi keramik, pekerja serta pengunjung. Informasi yang didapatkan dari evaluasi ini diharapkan dapat menjadikan kawasan pengrajin ini lebih berwawasan lingkungan perilaku dan menarik bagi wisatawan
\end{abstract}

Kata kunci : perilaku, pengrajin keramik, evaluasi tataruang

\begin{abstract}
Ceramic craftsmen have a specific activity that makes and sells ceramic products, the activities need a well-ordered space for more effective and efficient production process. The existence of the space currently used
\end{abstract}

PAWON: Jurnal Arsitektur, Nomor 01 Volume II, Bulan Januari-Juni Tahun 2018, ISSN 2597-7636 
for production and

showroom is the function of space, which used to be part of the dwelling house; this time functioned optimally and this condition is a spatial design product by the community. Spatial planning evaluation aims to determine the current spatial design performance, so it can provide advice if the problem is obtained and maintain the design if the spatial order already has a performance environmentally sound behavior. There are 3 scopes of the study to conduct the evaluation, first to do a micro study that knows the function of space for the production process and showroom, the second to do meso study that knows the order of production and showroom with the environment, the third to do macro studies that know the potential of the environment in supporting the area ceramic craftsmen. The three environmental studies involved owners of ceramic production sites, workers and visitors. The Information obtained from this evaluation is expected to make this craftsman area more environmentally friendly behavior and attractive to tourists.

\section{Keywords : behavior, ceramic artisans, spatial evaluation}

\section{PENDAHULUAN}

Keberadaan sentra Kerajinan Keramik Dinoyo kota Malang, merupakan salah satu dari 5 sentra kerajinan keramik terbesar di Indonesia. Eksistensinya semakin menguat dengan didirikannya Pabrik Keramik Dinoyo pada tahun 1957, kemudian masyarakat Dinoyo juga merintis pembuatan keramik pada tahun 1958. Pada tahun 1998, didirikan Paguyuban Perajin dan Pedagang Keramik Dinoyo dengan tujuan agar kegiatan sentra Kerajinan Keramik Dinoyo dapat dilestarikan sebagai salah satu produk unggulan ekonomi kreatif Kota Malang; hal tersebut juga mendasari dibentuknya lingkungan Kawasan Kampung Wisata Keramik Dinoyo. Kegiatan kawasan pengrajin disini memproduk keramik yang berupa vas bunga, gelas, hiasan dinding hingga macam-macam souvenir.

Harapan Paguyuban tersebut memang perlu ditindaklanjuti secara positif, mengingat kesan yang didapatkan pada kawasan keramik Dinoyo saat ini adalah kurangnya ekspos budaya pembuatan keramik serta sulitnya mendapatkan fasilitas tempat parkir kendaraan pada saat berada pada toko atau ruang pamer untuk mendapatkan suatu produk guna pemenuhan kebutuhan. Pencanangan sebagai kawasan kampung wisata keramik, merupakan momentum yang membutuhkan suatu peran bersama antara para pengrajin dan pekerja, serta pedagang keramik untuk memelihara dan melindungi sumber daya alam yang berupa budaya pembuatan keramik sebagai kearifan lokal yang dapat memberikan manfaat bagi masyarakat yang tinggal di kawasan Dinoyo.

Selama ini, keberadaan tapak atau lokasi beberapa pengrajin dan atau 
pedagang keramik merupakan bagian dari tempat tinggal sehingga fungsi ruang tersebut merupakan alih fungsi kegiatan dari yang dulunya sebagai ruang tamu, ruang keluarga, ruang tidur maupun garasi. Hal ini, menjadikan rancunya tata ruang antara kegiatan tempat produksi keramik maupun ruang pamer dengan tempat tinggal suatu keluarga. Apapun hasilnya, hal tersebut merupakan hasil rancangan asli dari masyarakat kawasan keramik Dinoyo. Pada tempat produksi keramik didapatkan kegiatan pada satu ruang yakni proses pembentukan keramik dan pengeringan, maupun pembakaran keramik, sedangkan pada ruang yang lain didapatkan kegiatan mendekorasi keramik menyatu dengan pengglasiran serta pembakaran keramik; kebutuhan pencahayaan dipasok dengan cahaya buatan, demikian juga penghawaannya menggunakan penghawaan buatan dengan kipas angin. Kegiatan pada ruang pamer, didapatkan proses pengepakan, pengecatan benda souvenir, penempatan kiriman barang yang baru datang serta barang yang akan dikirim, akibatnya apabila ada pengunjung yang akan mengamati barang akan menjadi terganggu karena tatanan barang menutupi sirkulasi manusia maupun barang dalam ruang.

Persepsi lingkungan, menurut Haryadi (2010) di interpretasikan berdasarkan seting oleh individu berdasarkan latar belakang budaya, nalar serta pengalamannya. Dalam kajian arsitektur lingkungan dan perilaku, menekankan ragam dan kesamaan persepsi lingkungan beberapa individu atau beberapa kelompok individu; hal tersebut selaras dengan pendapat Stokols (1977), yang menyatakan bahwa hubungan antara lingkungan dan perilaku membutuhkan kajian antara kelompok manusia dengan lingkungan fisik, lingkungan sosial serta lingkungan kultural. Diperjelas oleh Joyce (2004), bahwa hubungan antara lingkungan dan manusia serta perilakunya adalah hubungan timbal balik, saling terkait dan saling mempengaruhi; sehingga kita tahu mana yang merupakan sebab dan mana pula yang merupakan akibat. Pada konteks pemahaman tentang lingkungan pengrajin keramik di kawasan Dinoyo, merupakan wadah kegiatan masyarakat yang memiliki budaya membuat keramik dan memamerkan keramik dengan segala fasilitas yang disediakan, serta berusaha memenuhi ketentuan kenyamanan pada saat beraktivitas yang dilakukan oleh pekerja, maupun pemilik, serta menerima pengunjung yang membutuhkan produk kerajinan mereka. Evaluasi penataan ruang pada kawasan pengrajin dimaksudkan dapat mengetahui kinerja rancangan tempat produksi keramik maupun ruang pamer, lebih luas lagi adalah fungsi ruang-ruang tempat produksi keramik maupun ruang pamer dengan lingkungan sekitarnya, serta mengetahui kinerja tatanan kawasan pengrajin keramik Dinoyo. Sebagai harapan untuk keberlanjutan kawasan pengrajin, dibutuhkan penataan ruang kawasan pengrajin keramik yang berwawasan lingkungan perilaku serta melengkapi segala aspek yang meliputi prasarana maupun sarana agar keberadaannya akan bertambah nyaman dan berfungsi sebagai

PAWON: Jurnal Arsitektur, Nomor 01 Volume II, Bulan Januari-Juni Tahun 2018, ISSN 2597-7636 
kawasan untuk berwisata guna meningkatkan ekonomi masyarakat setempat agar mereka makin sejahtera, makmur, tertib dan indah.

\section{TINJAUAN PUSTAKA}

Menurut Stokols (1977), perkembangan kajian arsitektur lingkungan dan perilaku penting memperhatikan tiga tingkatan kajian atau analisis yang dilakukan dalam studi arsitektur lingkungan dan perilaku yakni tingkat mikro, menengah serta makro. Pada tingkatan mikro dilakukan kajian yang berhubungan dengan perilaku individu-individu dalam seting tertentu misalnya pada kamar; dengan menitikberatkan pada warna ruang, ukuran dan bentuk, perabot dan penataannya serta elemen yang mempengaruhi kondisi dan perilaku pemakainya yakni suara, temperatur serta pencahayaan. Pada tingkatan menengah atau meso, melakukan kajian pada rumah dan lingkungannya, adapun kajian yang dilakukan meliputi kultur karena merupakan respons pragmatis terhadap iklim dan lingkungan rumah tersebut dibangun, faktor berikutnya adalah religi yang berkaitan dengan bentuk dan pola rumah dan perumahan tradisional, serta faktor perilaku yang secara dialektis saling mempengaruhi antara lingkungan fisik dan perilaku penghuninya dalam hal ini perlunya pengamatan keberadaan fasilitas secara bersama misalnya MCK, air bersih dan lainnya. Pada tingkatan makro, perlu mengamati proses interaksi yang kompleks yakni memberikan perhatian pada peran faktor-faktor individu dalam mengkaji lingkungan perkotaan secara lebih manusiawi. Berkaitan dengan itu, Rapoport (1977, 278-279) mengusulkan beberapa unsur yang perlu dikaji diantaranya ruang kegiatan manusia, area inti yang dikendalikan oleh sekelompok penduduk kota, teritori yang merupakan area yang spesifik dimiliki dan dipertahankan dengan aturan-aturan atau norma-norma tertentu, area terkendali yang dikuasai dan dikendalikan oleh sekelompok penduduk kota, serta ruang personal.

Proses kajian yang lebih terukur, membutuhkan kajian awal tentang studi lingkungan perilaku pada kawasan pengrajin keramik guna mencari konsep perancangan arsitektur di kelurahan Dinoyo kota Malang (Adhi dkk, 2016) mendapatkan hasil tentang pentingnya menentukan bangunan berada pada lahan yang tidak berkontur, kejelasan pencapaian menuju pengrajin beraktivitas, penentuan bentuk bangunan yang spesifik agar persepsi fungsi bangunan mudah dipahami, fungsionalitas bangunan perlu dijabarkan sesuai organisasi ruang yang sederhana namun jelas demikian juga orientasinya, serta peranan manusia sebagai subyek perilaku diposisikan sebagai hal yang perlu diperhatikan guna memperkecil permasalahan pada tujuan perancangan.

Selama ini, psikologi lingkungan seperti disebutkan oleh Haryadi 
(2010) hakekatnya adalah mempertanyakan faktor peran proses-proses psikologis (misalnya persepsi, kognisi dan privasi). Persepsi lingkungan atau environmental perception adalah interpretasi tentang suatu seting oleh individu tersebut; setiap individu akan mempunyai persepsi lingkungan yang berbeda karena latar belakang budaya, nalar serta pengalamannya. Kognisi lingkungan adalah proses untuk memahami dan memberikan arti terhadap karakteristik lingkungan pengrajin keramik dalam beraktivitas yang kemudian dilengkapi dengan kajian penataan ruang pamer sehingga didapatkan fleksibilitas ruang, sirkulasi, penghawaan, pencahayaan serta penataan objek pamer. Karakteristik privasi lingkungan memiliki fungsi dan merupakan bagian dari komunikasi (Joyce, 2004).

\section{METODE PENELITIAN}

Melakukan persiapan, yaitu mempersiapkan peralatan yang diperlukan dalam pengumpulan data : kamera untuk merekam keadaan di lapangan, distometer untuk mengukur panjang ruang, lux meter untuk mengukur pencahayaan, kertas, buku catatan dan alat tulis/gambar.

Pengumpulan data dilakukan dengan mengadakan observasi lapangan, wawancara, pemetaan perilaku dan studi dokumentasi. Data dikoleksi dengan dicatat, dipetakan, digamnbar, disketsa, difoto maupun direkam. Data-data awal untuk mengevaluasi kinerja rancangan ruang pamer dan ruang produksi keramik, kemudian diperluas melibatkan lingkungan disekitarnya, serta seluruh kawasan wisata keramik Dinoyo Malang dengan cakupan penelitian: keberadaan ruang yang meliputi ruang pamer dan tempat produksi keramik; keberadaan ruang pamer ataupun tempat produksi dan lingkungannya serta keberadaan ruang pamer maupun tempat produksi keramik dan kawasan pengrajin keramik.

Pengamatan ruang pamer maupun tempat produksi keramik dimaksudkan untuk mengetahui kinerja fungsi ruang, tatanan ruang serta kenyamanan bagi pengunjung maupun pengelolanya. Kondisi rancangan ruang pamer dan lingkungannya digunakan untuk mengetahui interaksi dalam lingkup kultur dan faktor perilakunya, sedangkan kondisi rancangan kawasan dikaitkan dengan ruang pamer atau tempat produksi keramik untuk mengetahui kinerja rancangan secara makro.

\section{HASIL DAN PEMBAHASAN}

Persepsi tentang optimalisasi fungsi ruang oleh pemilik tempat produksi keramik adalah menjadikan ruang akan dipenuhi oleh berbagai material keramik dan alat untuk memproduknya serta mengabaikan sirkulasi pekerja maupun alat produksi sehingga menjadikan suasana ruang menjadi sesak dan mengabaikan kenyamanan untuk bekerja sesuai tuntutan perilaku; hal tersebut juga terjadi pada ruang pamer yang dipenuhi oleh

PAWON: Jurnal Arsitektur, Nomor 01 Volume II, Bulan Januari-Juni Tahun 2018, ISSN 2597-7636 
berbagai barang dagangan serta terjadi tumpang tindih aktivitas antara ruang pamer, ruang pengepakan dan gudang sehingga mengabaikan kenyamanan sirkulasi pengelola ataupun pengunjung dalam memilih atau

mengamati benda yang diinginkan.

Pengrajin keramik Dinoyo, berada pada RW 03 Kelurahan Dinoyo Kota Malang, keberadaan mereka tersebar pada RI 1, RI 3 dan RI 6. Kegiatan para pengrajin ini diwadahi pada tempat produksi keramik, ruang pamer serta tempat tinggal yang juga memproduksi souvenir.

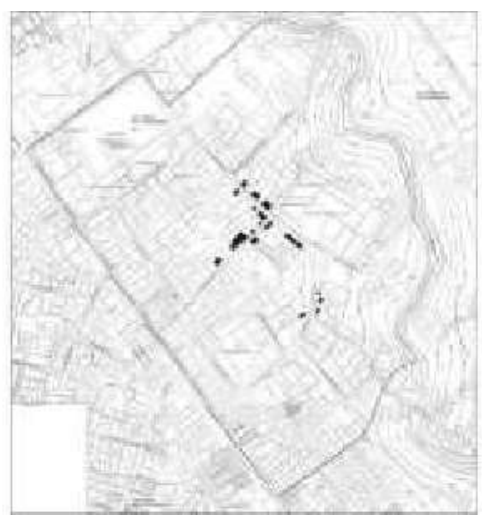

Gambar 1. Peta RW 03 Kelurahan

Dinoyo Kota Malang

Pada tingkatan lingkungan mikro, tempat produksi keramik, memiliki karakteristik ruang yang dapat mewadahi aktivitas pengolahan bahan yakni mengolah bahan baku yang terdiri dari kaolin atau tanah liat, felspard (batuan), kwarsa (pasir) dan ball clay (tanah liat), tujuannya adalah membuat keramik plastis yang siap pakai; setelah pengolahan bahan dilanjutkan dengan pembentukan keramik yang mengubah bongkahan badan keramik plastis menjadi benda-benda yang dikehendaki dengan pembentukan tangan langsung (handbuilding), teknik putar (throwing) dan teknik cetak (casting); setelah benda keramik selesai dibentuk dilanjutkan dengan pengeringan dengan tujuan untuk menghilangkan air plastis yang terikat padat pada keramik, prosesnya dapat dilakukan dengan memanfaatkan panasnya sinar matahari atau mesin pengering; tahap selanjutnya setelah pengeringan adalah mendekorasi keramik dengan melukis benda keramik; dilanjutkan dengan pengglasiran yakni memberikan lapisan gelas pada benda keramik dengan cara dituang, disemprot atau dikuas, serta dicelup kedalam wadah yang berisi glasir; setelah pengglasiran dilanjutkan dengan pembakaran keramik yang merupakan langkah terakhir dan merupakan inti dari pembuatan keramik. Mengingat prosesnya yang berurutan, sebaiknya penataan ruang pada proses produksi ini memiliki pola tata ruang yang linier, namun pada kawasan pengrajin ini tidak ada kejelasan pada tata ruangnya akibatnya sirkulasi yang terjadi saat proses produksi terkesan

PAWON: Jurnal Arsitektur, Nomor 01 Volume II, Bulan Januari-Juni Tahun 2018, ISSN 2597-7636 
tidak teratur.

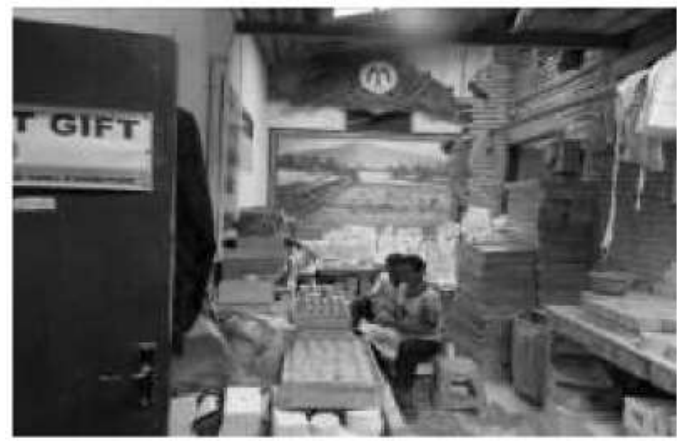

Gambar 2. Suasana Ruang Pembentukan Keramik

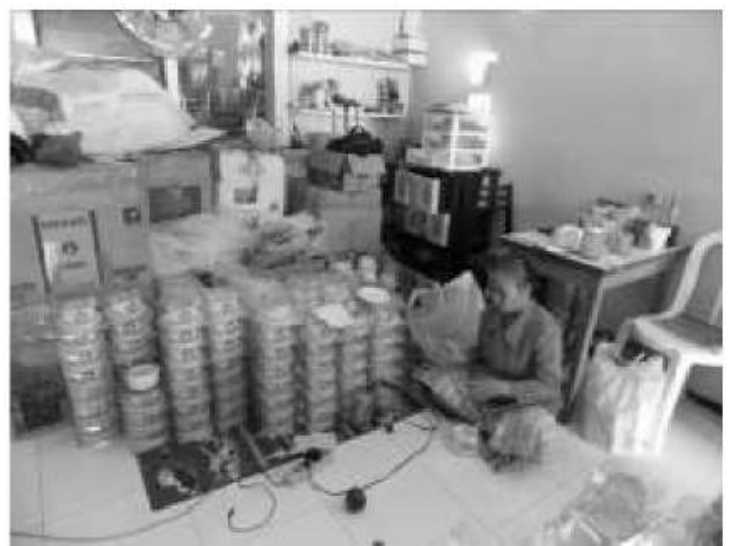

Gambar 3. Keberadaan suasana ruang pamer pada menunjukkan adanya tumpang tindih fungsi ruang pamer dengan tempat kerja maupun gudang

Hal ini menjadikan sulitnya para pengunjung untuk mengamati ataupun memilih barang yang diminatinya, serta timbulnya kesan sesak dan kumuh akan mengurangi kenyamanan karena tidak sesuai dengan tuntutan perilaku pengunjung. Pada tingkatan lingkungan meso, yakni mengkaji keberadaan tempat produksi keramik dan ruang pamer dengan lingkungannya. 


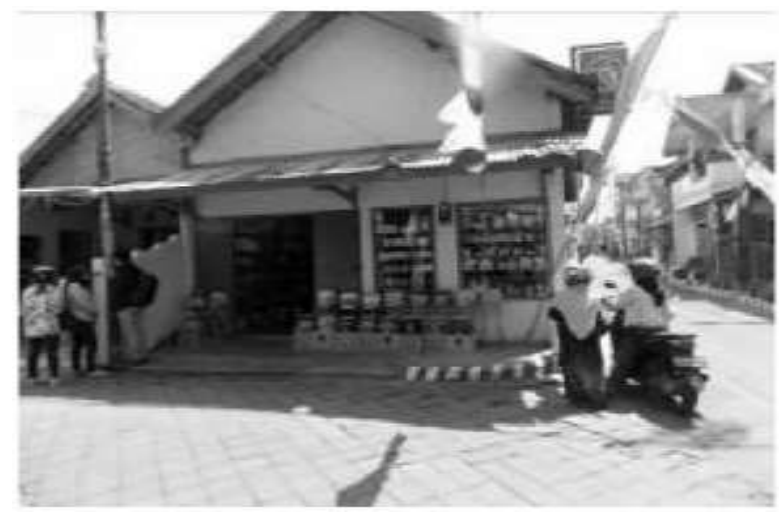

Gambar 4. Tidak adanya fasilitas parkir untuk pengunjung

Kajian ruang pamer dan lingkungannya, selalu memperhatikan kultur pelakunya yakni pemilik dan pekerja agar dapat mengekspresikan komoditi yang dijual agar dapat menarik pengunjung. Demikian juga keberadaan pengunjung ingin difasilitasi serta dihargai agar nyaman dalam membeli guna pemenuhan kebutuhannya. Tidak adanya fasilitas parkir untuk pengunjung seperti pada Gambar 4, menunjukkan kurangnya perhatian para pemilik ruang pamer terhadap tuntutan kenyamanan pengunjung akan kultur perilaku sehingga kenyamanan mengunjungi ruang pamer tidak terpenuhi.

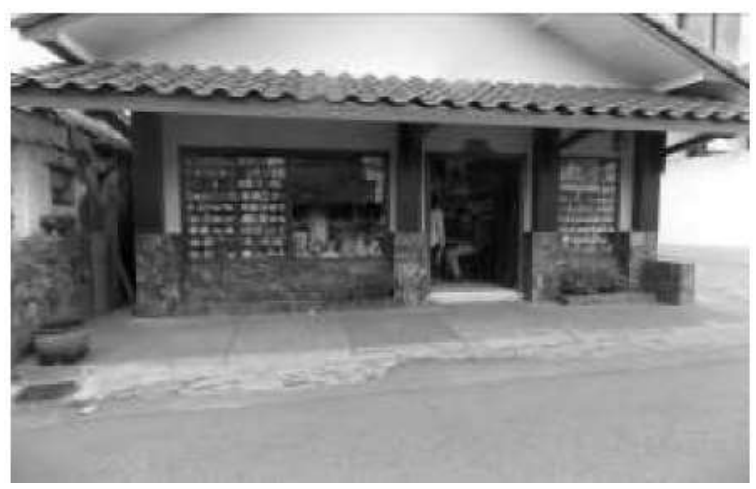

Gambar 5. Ruang Pamer yang menyediakan fasilitas parkir

Tersedianya fasilitas parkir pengunjung seperti pada Gambar 5, menunjukkan perhatian pemilik ruang pamer akan kenyamanan pengunjung sesuai kultur perilaku.

Pada tingkatan lingkungan makro atau perumahan dalam kajian 
arsitektur lingkungan kawasan pengrajin keramik Dinoyo memiliki area inti di kawasan bekas Pabrik Keramik Dinoyo yang berupa taman yang sering dipakai untuk kegiatan warga sekaligus merupakan landmark lingkungan pengrajin keramik. Aksesibilitas untuk pengunjung yang datang dengan alat transportasi kendaraan besar dapat menggunakan area parkir dalam halaman bekas pabrik keramik yang kurang dikenal oleh pengunjung di kawasan Dinoyo, sedangkan pengunjung yang datang secara pribadi dapat langsung menuju ruang pamer yang dituju.

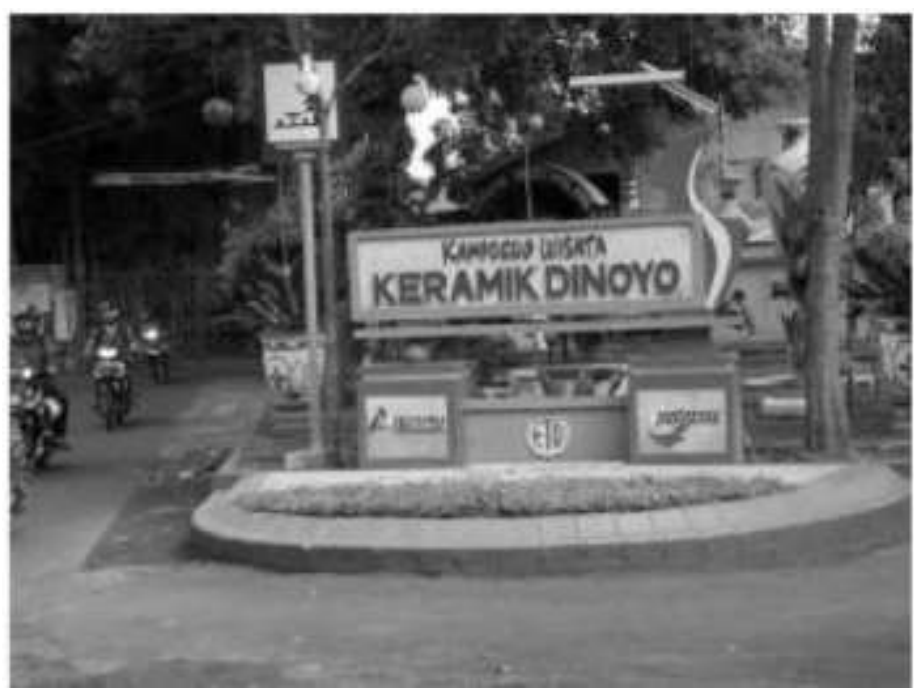

Gambar 6. Area inti pada kawasan pengrajin keramik Dinoyo

Pada area inti pada kawasan pengrajin keramik Dinoyo, tidak didapatkan peta mental yang memberikan informasi kepada pengunjung tentang tempat produksi keramik dan ruang pamer. Hal ini penting untuk mengetahui bagaimana manusia atau sekelompok manusia memanfaatkan, menggunakan atau mengakomodasikan perilakunya dalam suatu situasi waktu dan tempat yang tertentu, pemahaman tersebut menguatkan persepsi tentang kawasan yang memiliki budaya dalam pembuatan keramik sehingga menimbulkan rasa ingin tahu, kemudian tertarik untuk mengunjunginya. Fasilitas penghubung yang aman dan nyaman dari area inti menuju tempat produksi keramik ataupun ruang pamer perlu dipertimbangkan keberadaannya. Kedatangan para pengunjung baik pribadi, berkelompok maupun berombongan membutuhkan ruang penerima yang mengesankan akrab dan membuat mereka kerasan. 


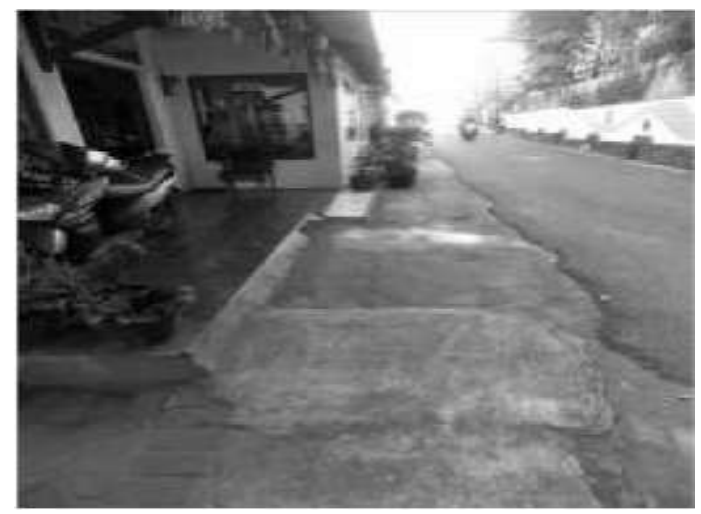

Gambar 7. Teritori untuk kendaraan dan pengunjung

Keberadaan teritori untuk kendaraan dan pengunjung pada Gambar 7, yang berupa jalan umum dan tempat pejalan kaki perlu diperjelas dan dipertegas guna kenyamanan penggunanya. Fasilitas ini perlu disediakan sesuai tuntutan aktivitasnya, selain itu juga perlu dipertimbangkan tentang kenyamanan berkaitan dengan adanya dua musim di Malang, yakni kemarau dan penghujan; hal tersebut dimaksudkan agar pejalan kaki tidak kepanasan maupun kehujanan.

\section{KESIMPULAN}

Perbedaan persepsi antara pemilik tempat produksi keramik akan optimalisasi fungsi ruang yang bermakna penempatan barang dagangan sebanyak mungkin sesuai kemampuan dengan tuntutan pengunjung akan optimalisasi kenyamanan layanan menjadi dasar untuk mengetahui kinerja rancangan oleh masyarakat pada kawasan pengrajin keramik di Dinoyo Malang.

Keberadaan para pengrajin keramik secara umum memiliki kebutuhan akan fasilitas untuk tempat bekerja memproduksi keramik serta memberikan informasi kepada para pengunjung yang ingin membeli produknya guna memenuhi kebutuhan ataupun koleksi karena karakteristik produknya. Fasilitas yang ada untuk wadah kegiatan tersebut pada objek kajian, merupakan ruang yang kurang memperhatikan perilaku penggunanya baik pemilik, pekerja serta pengunjung; karena keberadaannya pada satu sisi didasarkan atas optimalisasi pemenuhan tuntutan kebutuhan dengan mengalihfungsikan bagian dari ruangan suatu rumah tinggal pada sisi yang

PAWON: Jurnal Arsitektur, Nomor 01 Volume II, Bulan Januari-Juni Tahun 2018, ISSN 2597-7636 
lain pemenuhan kenyamanan membutuhkan kajian aktivitas secara optimal. Evaluasi penataan ruang pada kawasan pengrajin keramik yang berwawasan lingkungan perilaku, meliputi 3 aspek lingkungan yaitu :

a. Aspek lingkungan mikro, membahas tentang tata ruang pada tempat produksi dan ruang pamer. Pada tempat produksi didapatkan sirkulasi antar pekerja maupun pihak lain yang saling bersimpangan; keberadaan ruang pengering yang sangat terbatas sehingga menjadikan ruang lain difungsikan untuk kegiatan tersebut yang mengakibatkan tumpang tindihnya fungsi ruang; pencahayan dan penghawaaan yang kurang berfungsi dengan baik, sehingga membutuhkan pencahayaan dan penghawaan buatan yang kontinuitas pasokan sumber dayanya sangat mempengaruhi proses produksi. Pada ruang pamer, juga didapatkan terjadinya tumpang tindih fungsi ruang, yaitu ruang pamer, ruang kerja serta gudang, sehingga sirkulasinya antar manusia dan barang tidak lancar dan suasana ruang terkesan sesak; demikian juga fungsi pencahayaan dan penghawaan yang terbatas.

b. Aspek lingkungan meso, membahas tentang tatanan ruang antar tempat produksi keramik maupun ruang pamer serta lingkungan sekitarnya. Keberadaan fasilitas tempat parkir pengunjung yang merupakan pemenuhan kebutuhan faktor kultur dari perilaku telah dipenuhi oleh sebagian kecil pemiliknya.

c. Aspek lingkungan makro, membahas tentang area inti kegiatan pada kawasan pengrajin keramik yang berupa landmark sebagai tetenger tentang aktivitas kawasan pengrajin serta jalur penghubung antara landmark dengan ruang produksi ataupun ruang pamer. Kawasan ini perlu melengkapi fasilitas peta mental sebagai sarana informasi kepada pengunjung untuk mengetahui dengan mudah keberadaan tempat produksi dan ruang pamer, serta perlunya kejelasan dan ketegasan dalam memberikan fasilitas jalur penghubung yang berupa teritori agar stigma kawasan pengrajin keramik dapat menjadi destinasi wisata yang nyaman.

Perlu dilakukan penataan ruang secara bertahap dan berkesinambungan yang berwawasan lingkungan perilaku agar kenyamanan para pelaku kegiatan dapat terpenuhi serta mendukung wacana kampung wisata kerajinan keramik yang meningkatkan ekonomi para pengrajinnya.

\section{DAFTAR PUSTAKA}

Adhi Widyarthara, dkk. 2016. Studi Lingkungan Perilaku pada Kawasan Pengrajin Keramik Guna Mencari Konsep Perancangan Arsitektur di Kelurahan Dinoyo, Kota Malang.

Joyce Marcella Laurens. 2004. Arsitektur dan Perilaku Manusia. Jakarta: PT Grasindo. 
Haryadi, Setiawan B. 2010. Arsitektur, Lingkungan dan Perilaku Yogyakarta: Gadjah Mada University Press.

Rapoport, Amos. 1977. Human Aspect of Urban Form. Oxford: Pergamon Press.

Stokols, Daniel, 1977. Prespectives on Environment and Behavior: Theory, Research, and Applications. New York: Plenum Press.

Mc. Shane, W.R and Roess, R.P. 1990. Traffic Engineering. New Jersey: Prentice Hall.

Pemerintah Kota Surabaya. 1996. Pedoman Perencanaan dan Bangunan Fisik Bidang Tata Ruang Wilayah Kotamadya Surabaya Tahun 1996. Surabaya. 